moment, having no access to a reference library, I speak with diffidence, but so far as I have read and have been able to discover from the books at hand syphilis is not mentioned as a direct cause of glaucoma except by way of iritis.

The patient, an Italian labourer, aged 36 years, was admitted into the Nile Reservoir Hospital at Assouan on Feb. 2nd, 1901. I had been told that a man was lying ill at the works in one of Messrs. Aird's barracks and that he was1 vomiting and in great pain. When I saw him in the room he was obviously suffering from acute purulent conjunctivitis of both eyes; he was rolling about with pain in his supra-orbital and right temporal regions, and from time to time he vomited spasmodically a watery bile-stained fluid. I was told by his comrades that he began to vomit and to complain of the severity of the pain about 18 hours before I was called to him, though "for some time" he had been ailing and not at work, partly from his "bad eyes" and partly from syphilis from which he was then suffering.

On examination at the hospital the patient was found to be literally covered with secondary macular and papular syphilides. He was very anæmic and looked ill and thin and it was elicited that he had been living for some time past on the charity of other Italian workmen and had been getting very little to eat. He complained of intense pain over the brow and in the right temple and on more careful examination he was found to have the symptoms of acute glaucoma of the right eye which was of stony hardness with an anæsthetic and ground glass cornea, injected episcleral vessels, and absolutely no perception of light. It was very difficult to examine the eye owing to the severe purulent conjunctivitis with its accompanying chemosis. The tension in the left eye was normal. According to his own account his vision had been good, apart from a certain amount of sub. acute conjunctivitis, till about 24 hours before when he began to get a fogged vision which was rapidly followed by the severe browache and spasmodic vomiting and a rapid increase in the conjunctivitis. Owing to the purulent inflammation of his conjunctiva any operative measure such as iridectomy or sclerotomy seemed to me to be impossible and I had to be content with the administration of morphia hypodermically, cocaine and eserine instillation, and hot applications locally, with at the same time active anti-syphilitic treatment by free mercurial inunction, a generous diet, and attention to his general miserable condition. There was no remission or improvement in vision, though the eye gradually became less painful and somewhat less tense and the cornea cleared slightly: when he left the hospital the affected eye was stone blind. Beyond the conjunctivitis nothing could be detected in the remaining sound eye as regards its tension, its visual acuity, or the condition of the fundus.

The previous history of the case showed that in December, 1900, the man had been an in-patient of the hospital suffering from phagedæna of the penis grafted on a Hunterian chancre under a phimotic prepuce. He was much debilitated, neglected, and in a foul condition on admission. However, with a prompt opening up of the phagedænic area, the application of pure phenol after removal of the sloughs, and continuous immersion in boric acid hip baths he rapidly improved though he lost much of his glans penis. When discharged from the hospital he was warned to attend for a regular course of treatment but was not seen again till he was admitted for the glaucomatous attack.

It is difficult to say what was the cause of this violent glaucoma which after a period of 24 hours ended in stoneblindness. The patient was very definite in his statement that he had never had any eye trouble beyond attacks of the common Egyptian ophthalmia and no history of iritis or atropine instillation was to be had, and except for the severe secondary syphilis I know of no cause. Glaucoma has been known to occur in eyes affected with hæmorrhagic retinitis and this retinitis has been known to occur in secondary syphilis, but against this as a cause must be set the fact that the patient was not himself aware of any previous loss of vision. The rapidity of the destruction of sight and the fact that there was no remission, complicated with the pus in the conjunctiva, rendered it a hopeless case from the onset, while the severity of the symptoms may to an extent be probabiy attributed to the cachexia of want and disease.

There is another point to which this case draws attention. It appears that this man had been living on the charity of the other Italian workmen employed on the dam by Messrs. Aird as he was without money, having been out of work. Previously to his first admission in December he had been for some time out of work and owing to the nature of his malady had not been drawing sick pay from the sick fund jointly provided by Messrs. Aird and the men, which was by ts rules not available for persons suffering from venereal disease. Moreover, according to the strict rule of the hospital treatment for such cases was supposed to be paid for by the men and not provided gratis, and this was the reason the man gave for not attending for further treatment of the syphilis. The result of all these conditions was hat he got neither proper food nor treatment, and such a ase to my mind goes a long way to support the contention which has been brought forward so often at continental congresses, that it is really in the end false economy speaking in the wider sense of the relations of the individual to the general cosmos) to legislate either privately or publicly in a repressive and hostile sense as regards venereal disease. It is true that these diseases are contracted as the result of self-indulgence, but there is a great deal to be said for those who contend that it results in economic waste to put undue obstacles in the way of free treatment for these persons, who deserve attention not as criminals but as persons suffering from a disease which is not only highly contagious but in one of its forms may be transmitted to offspring. At present in England this view is not popular either with the profession or with those whose work brings them in contact with this question, but there is a good deal to be said for the proposition that when the Magdalene of the lock hospital and the blennorrhoic of the out-patient room are treated by pious surgeons and mission ladies less as criminals and more as sick persons a decided step will be taken on what many think the more sound and humane way.

Assiout.

\section{NOTE ON A CASE OF TETANUS; INJECTIONS OF ANTITETANIC SERUM ; RECOVERY.}

By Daniel Mowat, M.D. Edin.,

CHIET CLINICAL ASSISTANT, ROYAI LONDON OPHTHALMIC HOSPITAL.

A WOMAN, aged 40 years, the wife of a farrier, whilst walking across the floor of her husband's forge trod upon a block of wood from which a large nail protruded about one and three-quarter inches. She was wearing soft felt shoes and the nail penetrated into the ball of the left great toe about one inch. I saw her on Sept. 3rd, 1903, and, judging by the pain on moving the great toe, the nail had penetrated the metatarso-phalangeal joint. The leg was very painful and somewhat swollen; the wound was septic and inflamed, movement of the toe causing great pain. Antiseptic dressings were applied to the wound and a mixture of chloral hydrate, morphine, and bromide of potassium was given to relieve pain and to induce sleep.

On Sept. 4th the patient complained of a feeling of stiffness in the muscles of the jaws and pain up the back. The pain in the toe was still severe but she had slept a few bours after taking the medicine. During the next few days the wound seemed to be clean and there was little pain on movement. The feeling of stiffness in the jaws had nearly passed away. On the 9 th and 10th the patient sat up for some hours, saw a few friends, and did household work contrary to orders, as I somewhat feared tetanus setting in. In spite of the medicine she did not sleep on the 10th and on the following day there was well-marked rigidity of the masseters and also of the muscles of the back, the abdomen, and the thighs. The jaws could scarcely be separated. On the following day the spasms were well marked and opisthotonos was present. The pain was very great and the patient was unable to speak. Antitetanic serum was procured from Messrs. Allen and Hanbury and ten cubic centimetres were injected into the abdominal walls. The patient had a quieter night but the spasms were very frequent. On the 13th another ten cubic centimetres of serum were injected, after which the spasms became less frequent. A red rash developed for some distance over the abdominal walls where the injections had taken place. On the 14th the patient was quieter but begged for the injection of serum as she experienced great relief after half an hour. As she was much better on the 15th no injection was given. On the 16th she was not so well, the jaws were firmly clenched, and the abdominal muscles were very rigid. Another ten cubic centimetres of antitetanic serum were injected. On the $17 \mathrm{th}$ and $18 \mathrm{th}$ the various muscles were still rigid but less painful. She was fed during the last few days through the trube of an ordinary feeding bottle passed 
between the gums, the patient having previously had her artificial teeth removed. On the 20 th and 21 st ten cubic centimetres of antitetanic serum were injected on each day, the patient's condition improving after each injection. In all, nine injections of ten cubic centimetres were given. From this time her recovery was uninterrupted, with the exception of the adductors of the thigh, which remained in a state of tonic spasm for several days after the other muscles had become quiescent.

This case is of interest for several reasons. First, the apparent rapid onset of tetanus, within 36 hours after the injury, and then the disappearance of the symptoms; secondly, after the excitement of seeing friends, the sudden reappearance of tetanus on the ninth day; and thirdly, how the spasms yielded to the antitetanic serum and how on Sept. 15th when no injection was given the spasms were very severe. I may say that this is the only case of tetanus in which I have had an opportunity of using the serum. The few other cases which $I$ have attended previously to the introduction of the serum all terminated fatally.

Amhurst-park, Stamford-hill, N.

\section{A CASE OF CHONDROMA ATTACHED TO THE SUB- MAXILLARY SALIVARY GLAND.}

By H. J. IlotT, M.D. Aberd., M. R.C.S. KNG., MEDICAL OFFICER, BROMLEY (KENT) COTTAGE HOSPITAL.

A TALL, rather anæmic girl, 16 years of age, was admitted into Bromley (Kent) Cottage Hospital on Jaly 28th. She had a hard, moveable, nodular growth in the right sub. maxillary region. It had been slowly developing for the past seven or eight years. It was then of about the size of a large walnut. The growth was removed by me on August 4th. It was situated beneath the deep fascia, was encapsuled, and by its base was adherent to the submaxillary salivary gland. On section the growth was firm and white, with a few small yellowish-brown patches of somewhat softer consistence. It was sent to the Clinical Research Association for examination and Mr. J. H. Targett reported as follows: "This tumour is a chondroma of the submaxillary salivary gland. It is well encapsuled and shows no signs of malignancy. There is much imperfect glandtissue mixed with the cartilage. It is now usually regarded as an endothelioma." The wound healed quickly and the patient was discharged on August 13th. "These growths have been noticed as occurring in connexion with the parotid glands, but as they are rare and $I$ have never heard of one in connexion with the submaxillary gland $I$ think the case is worth recording.

Bromley, Kent.

Seamen's Hospital, Cardif'F.-The new Seamen's Hospital at Cardiff is now approaching completion. The total cost will be about $£ 35,000$, towards which about $£ 17,000$ have been promised.

The National Association for the PreVENTION OF CONSUMPTION. - A meeting of the council of the association was held at 13 , Hanover-square, W., on Nov. 9th, Sir William Broadbent being in the chair. Previously to holding the council meeting a preliminary meeting of the general committee for making arrangements for the Paris Congress in 1904 was held. At this meeting Sir William Broadbent was unanimously elected chairman of the general committee and Dr. J. J. Perkins honorary secretary. An executive committee was also formed, consisting of 12 names. It was decided to invite members of the staffs of the various hospitals for diseases of the chest to join the general committee, as well as several influential laymen who are interested in the subject of consumption. It was also resolved that the medical officers of health from the counties as well as from the chief towns should be invited. The secretary read a précis of the replies from the medical officers of health of the metropolitan boroughs with regard to spitting in publichouses. It was resolved that the matter should be postponed and that no further action should be taken for the present as the whole subject was shortly to be considered by the Incorporated Society of Medical Officers of Health. The secretary reported that branches of the association bad been formed at the Aberyswyth University and at Adelaide, South Australia.

\section{A : Altirtor}

\section{HOSPITAL PRACTICE, BRITISH AND FOREIGN.}

Iulla autem est alia pro certo noscendi via, nisi quamplurimas et morborum et dissectionum historias, tum aliorum tum proprias collectas habere, et inter se comparare.-MorGaGNI De Sed. et Calls. Yorb., lib. iv., Proœmium.

\section{NORWOOD COTTAGE HOSPITAL.}

A CASE OF REMOVAL OF THE APPENDIX WITH CONCRETION; RECOVERY.

(Under the care of Dr. John H. Galton.)

A MAN, aged 23 years, was admitted into the Norwood Cottage Hospital on May 6th, 1903. The family history was good. In 1896 he had an attack of pain in the right iliac region and was in bed for six weeks. In 1898 he again had an acute attack and was then taken to St. Bartholomew's Hospital. On Dec. 15th he ate half a pound of raw chestnuts and on the 16th he was doubled up with severe pain which was accompanied by semi-collapse and cold sweats. His temperature was $99^{\circ} \mathrm{F}$. and his pulse was 100 The abdomen was slightly full and rigid and did not move on inspiration; it was tender everywhere, especially ovtr the right iliac fossa. There was rather more resistance at the right iliac fossa but nothing could be felt. The percussion note was resonant in both iliac fossæ. On the 18th he was seen by the surgeon who thought that there were no indications for immediate operation. On the 22nd in the right iliac fossa above Poupart's ligament there was a distinct swelling in the region of the appendix. On Jan. 11th, 1899, he was quite convalescent and was taken into a surgical ward for the purpose of examining the appendix, and on the 2 lst he was discharged without undergoing an operation. (These notes were copied by the patient from the bed card at St. Bartholomew's Hospital). After his discharge he went to Folkestone and while there had a slight return of pain. During the last three years he had had several attacks of pain in the same region but had never been laid up. On examination there was no dulness on percussion over the right iliac fossa, but two and a half inches above Poupart's ligament and parallel with it a line of hard tissue one inch long could be rolled under the finger which on examination at another time was found to be in a different position one inch away from the former, and just over the middle of Poupart's ligament was a small hard swelling of the size of a hazel nut.

On May 7th, at 11.30 A.M., chloroform was administered by Mr. A. Scott Turner by means of Junker's apparatus and Dr. C. E. Michael assisted at the operation. The abdomen was opened by an incision four inches long and two and a half inches above Poupart's ligament and the healthy omentum disclosed was found not to be adherent. A nodule of the size of the tip of the index finger pointing upwards represented the appendix which was thickened, one and a half inches long, and firmly adherent to the caput coli. The adhesions were divided with a sharp dissector and one ligature of sterilised silk was applied to a bleeding vessel. The appendix was tied half an inch from the colon, the free end was touched with pure carbolic acid, and the peritoneal edges were brought together with a suture of sterilised silk. The appendix showed hypertrophied walls and a very hard stercolith one inch long, there being at the free end one and a half turns as of a corkscrew, as if the hypertrophied appendix had been trying hard to get rid of it. The abdominal wound was closed with four deep silverwire sutures including the peritoneum and seven superficial horsehair ones and was dressed with sal alembroth gauze, cotton-wool, and spica bandage.

After the operation the pulse was 72 and good. On May 8th the pulse was 84 and the temperature was $98.4^{\circ}$ The patient complained of pain at the upper part of the abdomen. The progress continued to be good. On the 11th he was given half an ounce of castor oil at 3 P.M. and an enema of warm water at 8 P.M. On the 12 th, no action of the bowels having taken place, white mixture was given every four hours, On the 14th the bowels acted. All deep 